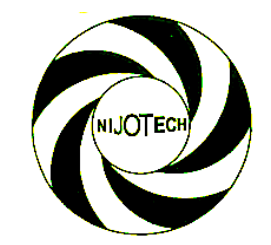

Nigerian Journal of Technology (NIJOTECH)

Vol. 39, No. 3, July 2020, pp. 744 - 751

Copyright@ Faculty of Engineering, University of Nigeria, Nsukka

Print ISSN: 0331-8443, Electronic ISSN: 2467-8821

www.nijotech.com

http://dx.doi.org/10.4314/njt.v39i3.13

\title{
ASSESSMENT OF INFRASTRUCTURE MAINTENANCE PRACTICES OF THREE AIRPORTS IN SOUTHERN NIGERIA
}

\author{
C. C. Okafor ${ }^{1}$ and M. N. Ezeoyili $2, *$ \\ 1, 2, Department of Civil Engineering, University of Nigeria, NsUKKa, ENUGu State, NIGERIA \\ E-mail addresses: ${ }^{1}$ chigozie.okafor@unn.edu.ng, ${ }^{2}$ m.nnamdi@gmail.com
}

\begin{abstract}
This research examined the maintenance plans and strategies used by three airports in Nigeria to ascertain how they maintain existing infrastructure for full assets utilization and safer operational capacities. Interviews and questionnaires were employed to get concise data from all the areas and infrastructure available at Akanu Ibiam International Airport, Port Harcourt International Airport and Margaret Ekpo International Airport. Descriptive statistics and ordinal logistic regression were used in analysis and report. While Akanu Ibiam International Airport employs preventive maintenance practices on most of their facilities, Port Harcourt International Airport and Margaret Ekpo International Airport adopt corrective maintenance practices. All the airports investigated suffer poor operational efficiency, dilapidating infrastructure and facilities, and lack maintenance actions. The maintenance schedule available at Akanu Ibiam International airport can serve as a template at Port Harcourt International Airport and Margaret Ekpo International Airport. This maintenance plan must be implemented in order to achieve improvement in operational capacities.
\end{abstract}

Keywords: Infrastructure, maintenance practices; airports; challenges; Akanu Ibiam; Port Harcourt; Margaret Ekpo

\section{INTRODUCTION}

An Airport houses many buildings, facilities, technology fixtures, traffic control systems, and personnel for smooth movement of people and cargos from a destination to another mainly through air carriage vehicles. The aviation sector contributes enormously to the Nigerian's economy and the Federal government must address infrastructural challenges with the purpose of ensuring safety and good ethical practices in the aviation sector [1]. Failure to address these challenges in the aviation sector would have serious effects on the tourism sector, the finance sector, and different businesses that depend on aviation sector markets [2]. Plane crashes in Nigeria were mainly due to faulty aircraft, lack of trained personnel in various airports, and lackadaisical attitude concerning maintenance practices [3].

In his report on the state of Air transportation in Nigeria, Ladan noticed the poor status of operational efficiency, unsafe operating environment, and backwardness of infrastructure in most airports in Nigeria [4].

\section{LITERATURE REVIEW}

\subsection{Research Overview}

The Aerodrome Maintenance Manual covers primarily, all the necessary duties required for aircraft operations in the course of the landing and take-off phases at the airport. It explains with maintenance sheets, how maintenance of facilities are taken and recorded for safe aircraft operations [5].

It is observed that equipment outages at airports can lead to increased delays, reduced safety, degraded capacity, severe economic repercussions and a good number of unsatisfied passengers [6]. Preventive maintenance reduces the incidence of breakdowns or malfunction of the facility or equipment making it usable at a reduced cost than corrective maintenance [7].

Proper maintenance results in the decrease of depreciation costs (resulting from longer economic life) and consequently leads to increased profitability [8]. Improper planning of maintenance of structures will give rise to uneconomic management practices that lead to the overspending of budgeted finances and a negative outcome in productivity of airports in the country [8].

\footnotetext{
* Corresponding author, tel: $+234-806-368-4757$
} 


\subsection{Maintenance Practices}

Maintenance can be categorized into two: Corrective and Preventive Maintenance [5]. Corrective maintenance is the type of maintenance that brings a failed or worn out item back to working order when it has failed or worn out. On the other hand, preventative maintenance are actions that prevent an item from failing, wearing out and lasting longer. Preventive maintenance often entails systematic inspection, detection of faults, and prevention of incipient failure [5].

\subsection{Economic Activities}

Airports in Nigeria generate revenue from both aeronautic and non-aeronautic sources. Aeronautic sources are revenue that depend on aircraft operations landing, parking, passenger service charge, air cargo charges, etc. Non-aeronautic revenue sources do not depend on aircraft operations - access gate fees, rents, airport adverts, VIP lounges, concession fees, etc. Nonaeronautic revenue sources usually are not directly related to aeronautical activities, however, they are becoming increasingly a good source of revenue generation for airports around the world [9].

\subsection{Concession}

Concession is achieved when the concession grantor offers full right to operate a facility and/or deliver a service of public interest to a service provider, in an agreement that the service provider (concessionaire) will build and manage the facility and/or manage the delivery of service at the concessionaire's own risk [10]. Airports must develop and improve their operational capabilities towards accommodating rising workload, which invariably results in increased working and capital costs as well as economies of scale efficiencies for airport operators [9]. Airport concession has the capacity to enhance the efficiency of airport operation; decrease the cost to the government for the support of airport sector, and attract private sector participation to free public resources for public services [11].

\subsection{Airport Infrastructural Maintenance}

An efficient air transport network can contribute to financial growth and increased development in a country. However, in Nigeria, there is a poor reputation of how effectively the air transport systems are developed and poor operational security [4]. A good maintenance plan involves an important inspection of facilities in order to keep these facilities working without issues. Scheduled checks are important plans followed from a list of plans which entails the type of check, report gotten from such checks, and method of evaluation leading to results from such checks [5]. An effective maintenance program will provide better economic value on the infrastructure and higher financial gains on expenses used for maintenance of facilities [12].

\subsection{National Carrier}

In 1999, bad management led to a crisis in the Nigerian Civil Aviation industry following the decline and near collapse of the Nigerian Airways; this bad management finally resulted in the Nigerian Airways declared bankrupt in 2004 [4]. Several factors that have led to the collapse of several airlines in Nigeria include the absence of a coherent air transport policy, bad management, decaying facilities, loose security, intermittent air crashes, etc [13]. Nigeria government hopes to start a new National carrier in partnership with private sector investors and its major hub will be Nnamdi Azikiwe International Airport, Abuja [14].

\section{METHODOLOGICAL APPROACH \\ 3.1 Study Area}

Akanu Ibiam International Airport, Enugu is on a point Latitude of $06^{\circ} 28^{\prime} 27.38^{\prime \prime} \mathrm{N}$ and Longitude $007^{\circ} 33^{\prime}$ 43.06" E. The runway at this airport measures 3 kilometers in length by 60 meters in width. The shoulder measures 7.5 meters by 7.5 meters. The runway orientation is $08 / 26$ [15].

Port Harcourt International Airport has a reference point Latitude $050056 \mathrm{~N}$ and Longitude 0065659E. It has two Runway Approaches 03 and 21 with Runway Surface inset threshold lights and elevated Runway edge lights. The runway at this airport measures 3000 meters by 60 meters and two rapid exits $35 \mathrm{~m}$ with $10.5 \mathrm{~m}$ shoulder into the apron. The shoulder length is 7.5m [16].

Margaret Ekpo International Airport, Calabar has a point reference Latitude $04^{\circ} 58^{\prime} 33.67^{\prime \prime} \mathrm{N}$ and Longitude $008^{\circ}$ $20^{\prime} 49.91^{\prime \prime} \mathrm{E}$. The runway measures 2450 meters by 45 meters. The runway orientation is $03 / 21$ [15].

\subsection{Research Strategy}

Three airports in the southern part of Nigeria were taken into consideration in this research - Akanu Ibiam International Airport, Port Harcourt International Airport, and Margaret Ekpo International Airport. Secondary data were sourced from published materials, articles, journals, and documents of relevant government institutions and agencies in Nigeria related to airport studies, questionnaires research and infrastructural maintenance plans [17]. The primary data was collected from the employment of interviews and questionnaires which were administered to passengers, airport staff, and officers in charge of respective positions at the airports [16].

\subsection{Questionnaire Design}

Three sets of different questionnaires were designed for this study - Passengers' questionnaires, staff 
questionnaires, and airline questionnaires. These questionnaires were designed to suit the state of infrastructure and maintenance plans at the airport [17]. The ratings of infrastructure on the questionnaires were answered by a choice among a scale of Poor, Need Improving, Satisfactory, Good, and Excellent by passengers, airport staff and airline staff. Airport and airline staff answered the current method applied in maintenance of facilities which is either Routine check (Preventive maintenance) or Repair/Replacement (Corrective maintenance). Finally, factors that influence the maintenance of facilities were rated on any choice of Strongly Disagree, Disagree, No Idea, Agree, and Strongly Agree by all the staff at the various airports.

\subsection{Result Interpretation}

As this study is based on quantitative and qualitative analysis, descriptive statistical analysis was used to categorize this work. The study described reports and investigated events at different airports [18]. Likert scale was used in the questionnaires to suit a statistical analysis. This took into account the rating of infrastructure on a scale of $1-5$ [19].

This data was represented on a computer statistical analysis program, Statistical Package for Social Sciences (SPSS) with values from 1.0 to 5.0, each representing the rating word used in the questionnaires. Percentages of responses, frequencies and mean rating scale was employed in the discussion of the results $[19,20]$.

Ordinal logistic regression was used to predict the type of maintenance practices on most infrastructure and facilities at the airport. The state of infrastructure and facilities were entered as the dependent variable while keeping the current method applied in facility maintenance as the independent variable as filled out on the questionnaires distributed [22].

Various results from the analysis which showed no maintenance pattern was adopted to fall under Corrective maintenance. This implies that the maintenance of such areas is handled by an external body or that the area will be left unmaintained for a longer period. Table 1 shows the rating interpretation adopted for this research.

\section{RESULTS AND DISCUSSION}

\subsection{Akanu Ibiam International Airport, Enugu}

$100 \%$ of the staff interviewed supported the idea of a national carrier with their reasons not limited to creating employment for Nigerians, rapid development in the air transportation sector, competitiveness with private airline operators, reduction and control of outrageous charges on air bound passengers by private operators, and revenue generation.

Figure 1 shows that $75 \%$ of staff disagrees with the idea of airport concession in the belief that private individuals will perform worse than the government.

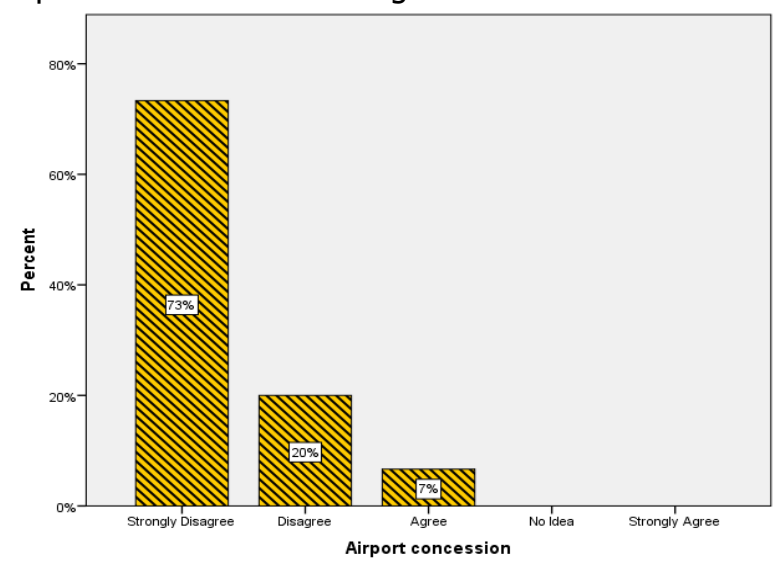

Figure 1: Support for Airport concession report from staff at AIIA

\subsubsection{State of infrastructure and facilities}

The Civil and Building department has a detailed maintenance plan but the schedules are not regularly followed. The maintenance histories are not kept or updated regularly. Most of the infrastructure and facilities were rated as areas requiring improvements as shown in Figures 2, 3, 4, and 5 .

This shows that these infrastructures lack good maintenance actions. The runway in this airport is currently in bad condition and need serious working/repair. There were reports of undulation and potholes on the runway by airline staff at the airport. This is a core part of an airport and poses a serious threat to the safety of aircraft and passengers using this airport.

Table 2 shows the results of the statistical analysis to rate the state of infrastructure and facilities and to predict the type of maintenance applied to them. The prediction analysis showed that this airport adopts both preventive and corrective maintenance practices on the infrastructure and facilities available. This validates their maintenance plan which is not regularly followed. Infrastructure without defined maintenance applied on them, for e.g. Runway, is maintained by an external body or lacks maintenance actions on them.

Table 1: Mean Rating Scale interpretation

\begin{tabular}{llll}
\hline Rating Scale & Rating Word & Analytical Meaning & Analytical scales \\
\hline 5 & Excellent & Best working condition possible & $4.51-5.00$ \\
4 & Good & Working well; no issues. & $3.51-4.50$ \\
3 & Satisfactory & Manageable, can be changed but not now & $2.51-3.50$ \\
2 & Need Improving & Currently in a bad condition but it is still in use at this moment & $1.51-2.50$ \\
1 & Poor & In a very bad state. Doesn't work & $0.00-1.50$ \\
\hline
\end{tabular}


This also confirms that the runway at the airport is in bad condition as reported by the airline staff at the airport. Mean ratings (B) show the current state of the different infrastructure and facilities based on Table 1. It affirms that most facilities at the airport require improvements

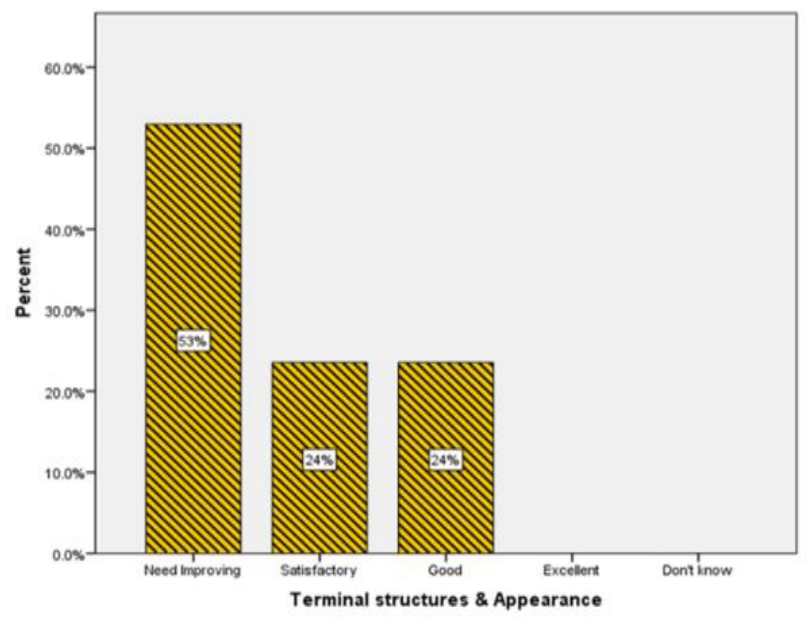

Figure 2: Terminal Structures Ratings at AIIA

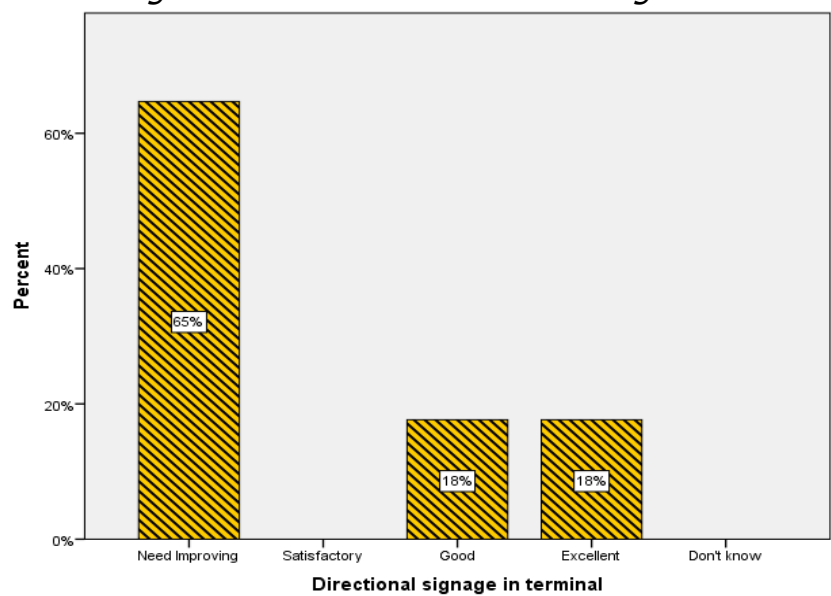

Figure 3: Directional signage Ratings at the airport and some are in terrible conditions. Table 3 shows the top ten factors that influence the maintenance of facilities in Akanu Ibiam International Airport

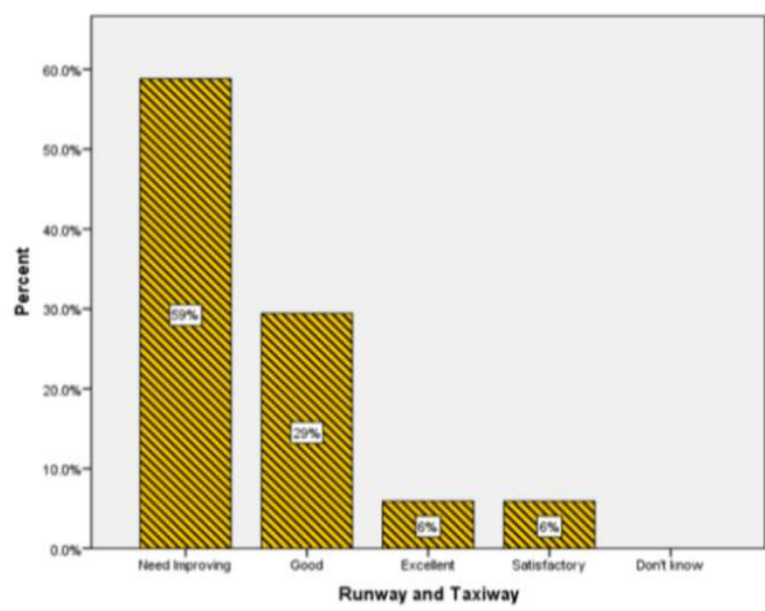

Figure 4: Runway ratings at AIIA

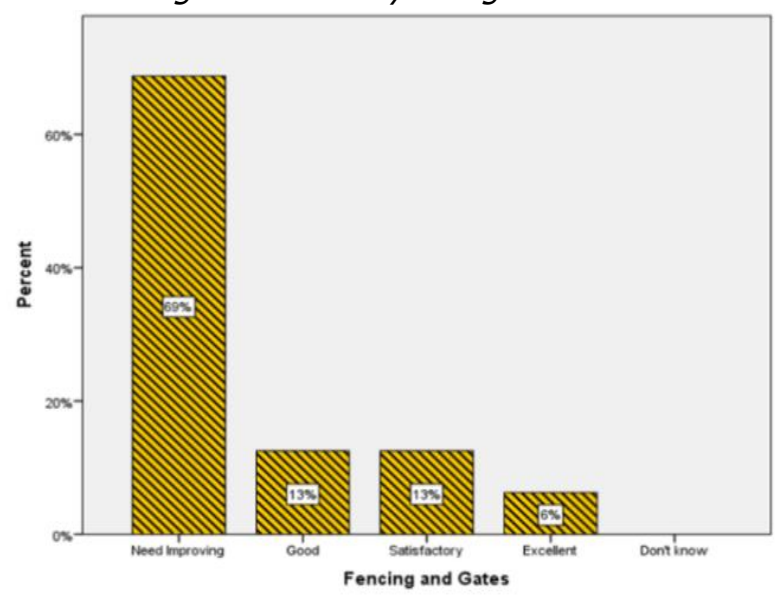

Figure 5: Fencing and Gates Ratings at AIIA

Table 2: Akanu Ibiam Airport Mean Ratings and Ordinal Logistic Regression Summary

\begin{tabular}{llllllllll}
\hline A & B & C & D & E & F & G & H & I & J \\
\hline Terminal Facilities & 2.94 & .949 & .949 & .011 & .186 & .000 & 0.66 & .949 & Corrective Maintenance \\
Terminal Structures & 1.65 & .704 & .710 & .012 & .179 & .006 & 0.63 & .710 & Corrective Maintenance \\
Directional Signage & 1.85 & .298 & .251 & .111 & 1.50 & .000 & 4.46 & .251 & Preventive Maintenance \\
Electrical Systems & 2.63 & .549 & .444 & .146 & 2.34 & .000 & 4.79 & .444 & Preventive Maintenance \\
Apron & 3.40 & .275 & .152 & .011 & .191 & .001 & 1.53 & 0.68 & Preventive Maintenance \\
Airfield Signs And Markings & 2.20 & .240 & .142 & .052 & .888 & .002 & 2.33 & .142 & Preventive Maintenance \\
Runway & 1.80 & .320 & .219 & .002 & .025 & .051 & .860 & Inv & No Defined Maintenance Applied \\
Fencing and Gates & 1.79 & .217 & .133 & .016 & .216 & .024 & 0.61 & 0.003 & No Defined Maintenance Applied \\
Drainage Systems & 1.60 & .341 & .276 & .050 & .727 & .002 & 2.80 & 0.005 & No Defined Maintenance Applied \\
Vehicles and Equipment & 2.00 & .097 & .049 & .046 & .761 & .001 & 0.46 & 0.020 & Corrective Maintenance \\
\hline
\end{tabular}

Source: SPSS Data Analysis

A - Infrastructure/Facilities, B - Mean Ratings, C - Pearson, D - Deviance, E - Nagelkerke R-Square, F - Wald, G - Sig. [Parameter Estimates], H - Exp (B) [Odds ratio], I - 2LogLikelihood, ] - Maintenance Practice Employed 
Table 3: Factors Influencing Maintenance of Facilities in Akanu Ibiam Airport

\begin{tabular}{llll}
\hline S/N & FACTORS & MEAN SCORE (SD) & RANK \\
\hline 1 & Inadequate Finance from government & $3.71(1.31)$ & 1 \\
2 & Inadequate maintenance plans & $3.59(1.18)$ & 2 \\
3 & Poor maintenance culture & $3.56(1.26)$ & 3 \\
4 & The high cost of maintenance practices & $3.53(1.12)$ & 4 \\
5 & Neglect of facilities & $3.47(1.12)$ & 5 \\
6 & Poor contract management & $3.41(1.00)$ & 6 \\
7 & Non-involvement of professionals in the planning process & $3.18(1.33)$ & 7 \\
8 & Poor Management & $3.06(1.14)$ & 8 \\
9 & Neglect from the Federal government & $3.06(1.52)$ & 9 \\
10 & Poor assets management & $3.00(1.32)$ & 10 \\
\hline
\end{tabular}

Source: Field Work

From Table 3, inadequate finance from government, inadequate maintenance plans and poor maintenance culture are the top factors affecting effective maintenance practices at the airport.

\subsection{Port Harcourt International Airport (PHIA)}

Seventy-seven percent $(77 \%)$ of the interviewed staff showed support for the government's idea for a National carrier stating reasons such as a source of revenue and foreign reserve generation for the government, youth employment, regulating airfare in the country, implementing high safety standards and good safety practices, and national identity.

\subsubsection{State of infrastructure and facilities}

The only available maintenance plan shows the quarterly maintenance schedule for the runway, taxiway, apron, and parking areas. There are many dilapidated infrastructures available at this airport with an average rating scale of 1.91 which falls into facilities that are in bad conditions and need serious repair or replacement. Some of the facilities at PHIA are either in bad condition and need serious repair, or not working at the time of this research. Figures $6,7,8,9$, and 10 show the percentages of different ratings from the questionnaires distributed.

Table 4 shows the results gotten after using statistical analysis on the questionnaires. In overall, Port Harcourt International Airport (PHIA) adopts a corrective maintenance approach (repair and replacement) on most of the facilities. This has led to more dilapidated infrastructure and facilities at the airport. Table 5 shows the top ten challenges influencing the maintenance of infrastructure and facilities at Port Harcourt International Airport.

From Table 5, theft and vandalism top the factors affecting the effective maintenance of facilities at this airport. This calls for proper strategic structures of security at PHIA. Inadequate maintenance plans and poor maintenance culture follows as observed in Akanu Ibiam International Airport, Enugu.

\subsection{Margaret Ekpo International Airport, Calabar 4.3.1 State of infrastructure and facilities}

Maintenance plans and strategies are unavailable at the airport. This airport adopts a corrective maintenance approach on all its facilities and infrastructure. Most of the available facilities at the airport have ratings of 1.51 - 2.50 (Table 1). This implies that most functioning facilities at the airport need improvements and others are in a very bad state.

Figures 11, 12, 13 and 14 show how passengers, airport staff and airline staff rated various facilities at the airport. Table 6 is the results of the statistical analysis of the questionnaires distributed at the airport.

The results (Table 6) show that this airport adopts a Corrective maintenance practice and some infrastructure are lacking a defined maintenance pattern which validates the lack of maintenance plan at Margaret Ekpo International Airport.

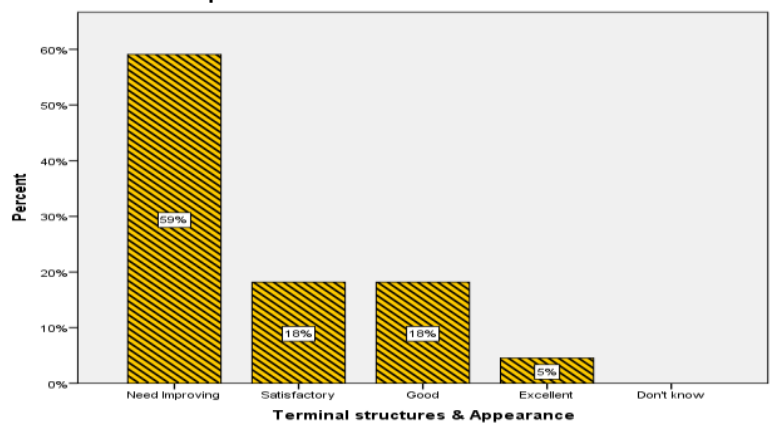

Figure 6: Terminal structure ratings at PHIA

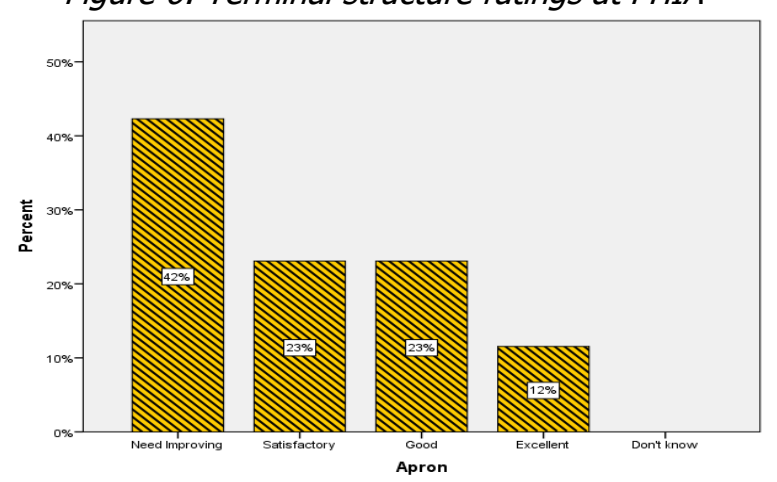

Figure 7: Apron Ratings at PHIA

Vol. 39, No. 3, July 2020 


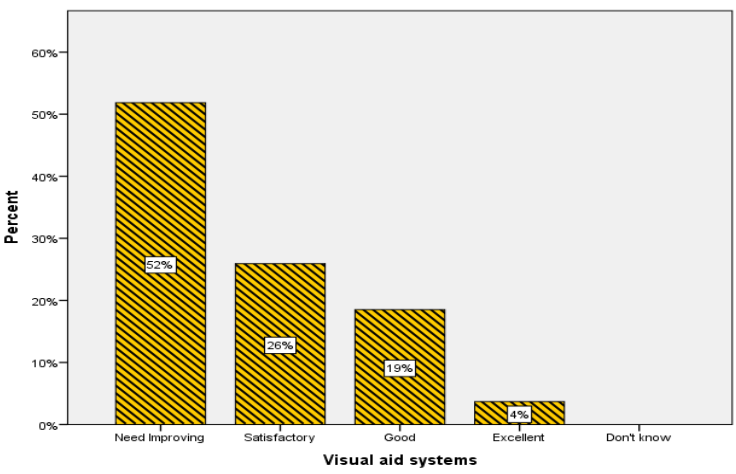

Figure 8: Visual Ratings at PHIA

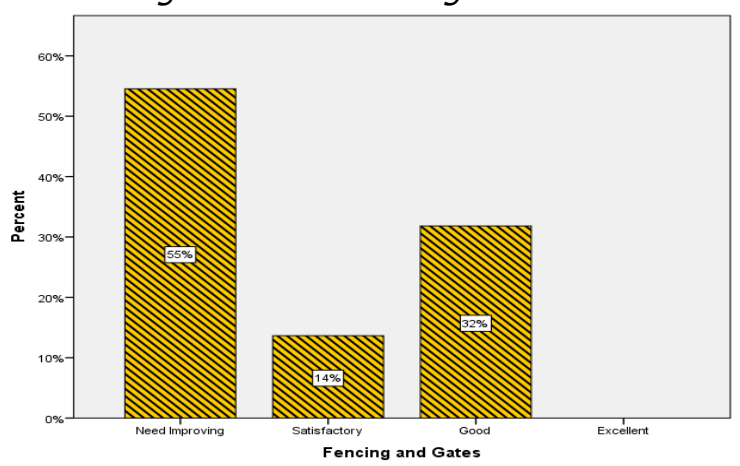

Figure 9: Fencing and Gates Ratings at PHIA

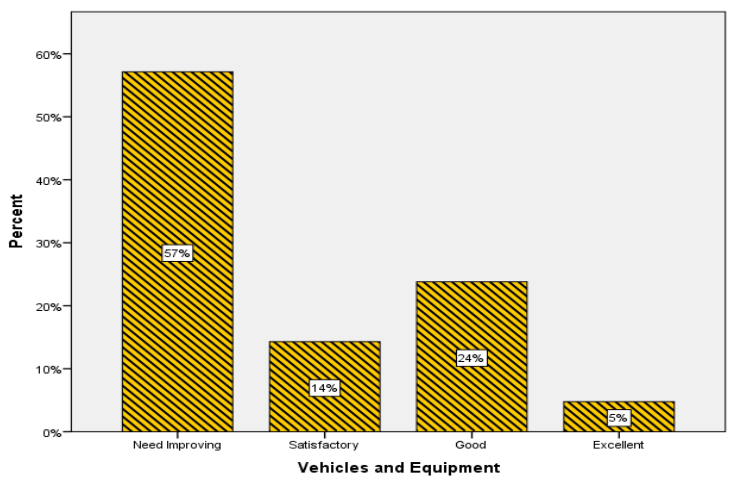

Figure 10: Vehicles and Equipment Ratings at PHIA.

Table 7 shows the top ten factors influencing the maintenance of infrastructure and facilities at the airport From Table 7, neglect of facilities, inadequate maintenance plans and poor maintenance culture are the top factors affecting effective maintenance practices at the airport. Without any maintenance plan available, most areas are neglected which lead to failures and decaying facilities at this airport.

Table 4: Port Harcourt International Airport Mean and Ordinal Logistic Regression Summary

\begin{tabular}{llllllllll}
\hline A & B & C & D & E & F & G & H & I & J \\
\hline Terminal Facilities & 1.41 & .535 & .570 & .124 & 2.72 & .009 & 0.25 & .570 & Corrective Maintenance \\
Terminal Structures & 1.68 & .253 & .237 & .025 & .861 & .001 & 1.83 & .001 & No Defined Maintenance Applied \\
Directional Signage & 2.09 & .532 & .520 & .013 & .243 & .002 & 0.67 & .520 & Corrective Maintenance \\
Electrical Systems & 2.14 & .947 & .947 & .002 & .040 & .000 & 0.85 & .947 & Corrective Maintenance \\
Apron & 2.09 & .895 & .896 & .000 & .009 & .002 & 0.92 & .896 & Corrective Maintenance \\
Visual Aid Systems & 1.78 & .327 & .268 & .003 & .055 & .000 & 0.81 & .268 & Corrective Maintenance \\
Airfield Signs And Markings & 2.32 & .244 & .160 & .027 & .552 & .004 & 1.96 & .004 & No Defined Maintenance Applied \\
Runway and Taxiway & 2.36 & .648 & .531 & .115 & 2.029 & .001 & 4.33 & .531 & Preventive Maintenance \\
Fencing and Gates & 1.77 & .789 & .787 & .000 & .008 & .009 & 1.08 & .787 & Corrective Maintenance \\
Drainage Systems & 1.81 & .418 & .294 & .184 & 3.310 & .006 & 5.82 & .294 & Corrective Maintenance \\
Vehicles and Equipment & 1.91 & .703 & .637 & .211 & 4.25 & .003 & 6.48 & .637 & Preventive Maintenance
\end{tabular}

Source: SPSS Data Analysis

A - Infrastructure/Facilities, B - Mean Ratings, C - Pearson, D - Deviance, E - Nagelkerke R-Square, F - Wald, G - Sig.

[Parameter Estimates], H - Exp (B) [Odds ratio], I - -2Log Likelihood, J - Maintenance Type Employed

Table 5: Factors Influencing Maintenance of Facilities at Port Harcourt International Airport

\begin{tabular}{llll}
\hline S/N & FACTORS & MEAN SCORE (SD) & RANK \\
\hline 1 & Theft and vandalism & $3.90(1.18)$ & 1 \\
2 & Inadequate maintenance plans & $3.76(1.22)$ & 2 \\
3 & Poor maintenance culture & $3.71(1.42)$ & 3 \\
4 & Purchase/use of materials contrary to specifications & $3.67(1.20)$ & 4 \\
5 & Poor Management & $3.59(1.33)$ & 5 \\
6 & Lack of quality materials for replacement & $3.59(1.40)$ & 6 \\
7 & Poor contract management & $3.55(1.34)$ & 7 \\
8 & Poor assets management & $3.52(1.21)$ & 8 \\
9 & Neglect of facilities & $3.41(1.30)$ & 9 \\
10 & Neglect from the Federal government & $3.29(1.27)$ & 10 \\
\hline
\end{tabular}




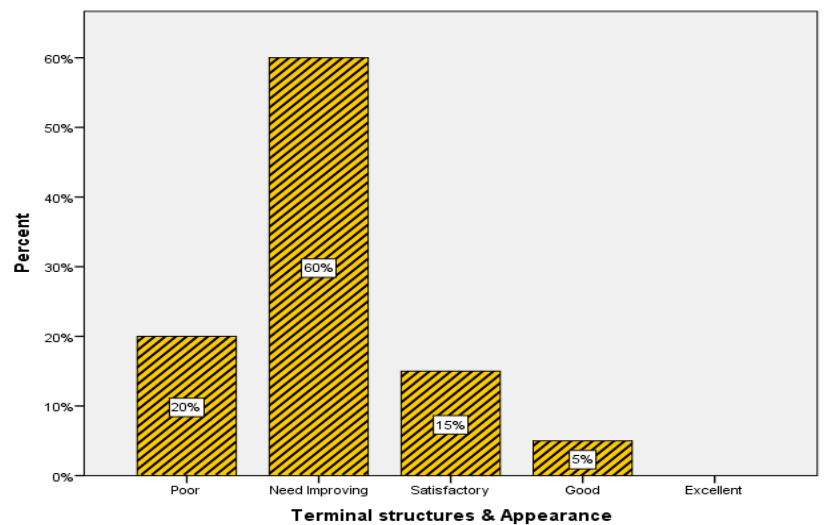

Figure 11: Terminal Structure and Appearance

Figure 12: Apron Ratings at the Airport

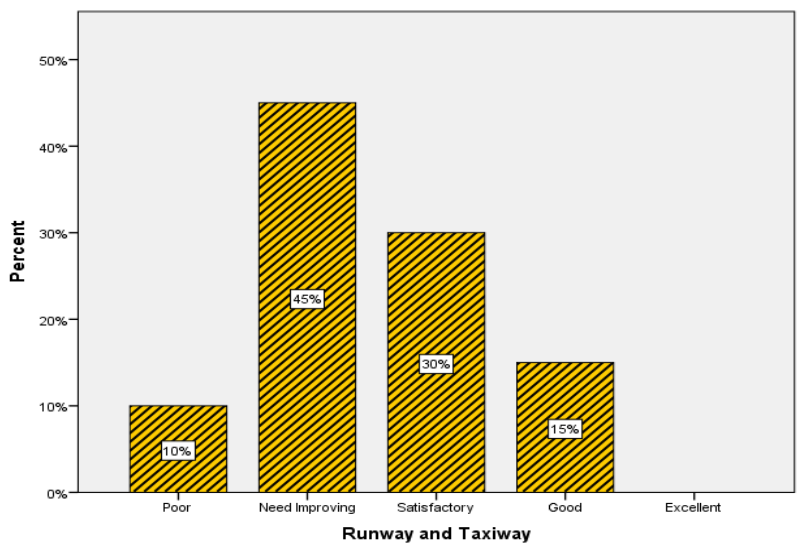

Figure 13: Runway Ratings at MEIA

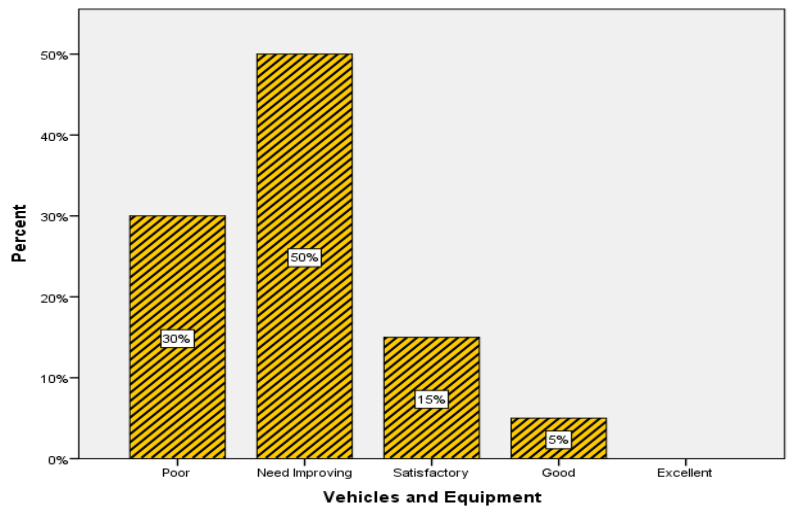

Figure 14:Vehicles and Equipment Ratings at MEIA

Table 6: Calabar Airport Mean Ratings and Ordinal Logistic Regression Summary

\begin{tabular}{llllllllll}
\hline A & B & C & D & E & F & G & H & I & J \\
\hline Terminal Facilities & 2.29 & - & - & - & - & - & - & - & No Defined Maintenance Applied \\
Terminal Structures & 2.05 & .839 & .752 & .174 & 2.56 & .001 & 6.99 & .752 & Preventive Maintenance \\
Directional Signage & 1.47 & .215 & .135 & .024 & .353 & .005 & 0.57 & .135 & Corrective Maintenance \\
Electrical Systems & 1.77 & - & - & - & - & - & - & - & No Defined Maintenance Applied \\
Apron & 2.47 & .116 & .066 & .079 & 1.39 & .002 & 6.23 & .056 & No Defined Maintenance Applied \\
Airfield Signs And Markings & 2.30 & .820 & .756 & .173 & 2.22 & .001 & 0.14 & .756 & Corrective Maintenance \\
Runway and Taxiway & 2.50 & .727 & .724 & .005 & .071 & .000 & 0.75 & .724 & Corrective Maintenance \\
Fencing and Gates & 1.71 & .329 & .255 & .009 & .108 & .000 & 0.69 & .255 & Corrective Maintenance \\
Drainage Systems & 2.35 & - & - & - & - & - & - & - & No Defined Maintenance Applied \\
Vehicles and Equipment & 1.95 & .038 & .018 & .100 & .141 & .003 & 0.28 & 0.18 & Corrective Maintenance \\
\hline
\end{tabular}

Source: SPSS Data Analysis

A - Infrastructure/Facilities, B - Mean Ratings, C - Pearson, D - Deviance E - Nagelkerke R-Square, F - Wald, G - Sig. [Parameter Estimates], H - Exp (B) [Odds ratio], I - -2Log Likelihood, J - Maintenance Type Employed

Table 7: Factors Influencing Maintenance of Facilities in Margaret Ekpo International Airport

\begin{tabular}{lllc}
\hline S/N & FACTORS & MEAN SCORE (SD) & RANK \\
\hline 1 & Neglect of facilities & $4.63(0.50)$ & 1 \\
2 & Poor maintenance culture & $4.53(0.52)$ & 2 \\
3 & Inadequate maintenance plans & $4.47(0.87)$ & 3 \\
4 & Poor Management & $4.44(0.81)$ & 4 \\
5 & Poor contract management & $4.41(0.87)$ & 5 \\
6 & Poor assets management & $4.29(0.85)$ & 6 \\
7 & Theft and vandalism & $4.06(1.12)$ & 7 \\
8 & Limited maintenance knowledge & $4.06(1.09)$ & 8 \\
9 & The high cost of maintenance practices & $4.06(1.09)$ & 9 \\
10 & Non-involvement of professionals in the planning process & $3.94(1.09)$ & 10 \\
\hline
\end{tabular}

Source: Field Work 


\section{CONCLUSIONS AND RECOMMENDATIONS}

Two international airports and a domestic airport in Nigeria were investigated to ascertain how they carry out maintenance actions on the available infrastructure and facilities. The results from this work show that most southern airports are poorly maintained and infrastructural maintenance practices are seriously lacking in Nigeria. A detailed maintenance schedule available in Akanu Ibiam International airport, Enugu, can serve as a template for other airports lacking maintenance plans, and this must be implemented in order to achieve infrastructural growths across airports Nigeria.

\section{RECOMMENDATIONS FOR FURTHER RESEARCH}

For further studies, the three international airports at Lagos, Abuja and Kano states can be looked into in order to make final recommendations on the best maintenance practice to adopt for all the airports in Nigeria. Proper maintenance plans, schedules, and amended aviation policies can be developed to suit all the airports in the country.

\section{REFERENCES}

[1] Eze Chinedu. "Nigeria: Addressing the Airport Infrastructure Deficit" www.allafrica.com/ stories/201802090737.html, Accessed on July 30, 2018.

[2] Darling, A. "The Future of Air Transport" White Paper. Statement by Rt Hon Alistair Darling MP, www.dft.gov.uk/aviation/whitepaper/statement/inde x.htm, Accessed on August 10, 2018.

[3] Odidi Godday. "Challenges facing the aviation industry www.247ureports.com/challenges-facing-theaviation-industry-in-nigeria/, Accessed on August 10, 2018.

[4] Ladan Iguda Suleiman, "An Analysis of Air Transportation in Nigeria", JORIND, Vol. 10, Number 2, 2012.

[5] Civil Aviation Authority Bangladesh. Aerodrome Maintenance Manual, First Edition, 2012.

[6] Rakasa Jasenka, Bauranov Aleksandar, Messika Benjamin, "Failures of critical systems at airports: Impact on aircraft operations and safety", Elsevier Journal publications, 2018.

[7] Eke Kelechi. Facility Maintenance of Building Infrastructure in Nigeria, 2016.

[8] Owolabi James D, Amusan Lekan M, Gani J, TunjiOlayeni $P$, Peter Joy, Omuh Ignatius, "Assessing the Effectiveness of Maintenance Practices in Public Schools", European International Journal of Science and Technology, Vol. 3 Number 3, 2014.

[9] Oyesiku, Olukayode.O. Somuyiwa, Adebambo.O.
Oduwole, Adewale.O. "Analysis of Airport Productivity and Efficiency Performance in Nigeria", European Journal of Business and Social Sciences, Vol. 4, Number 12, 2016, pp 147 - 168.

[10] Tsvetkov, A. Strategy for the development of the transport infrastructure of the Republic of Bulgaria through concessions mechanisms, Bulgarian Ministry of transport, information, technology, and communication, 2010.

[11] Adeniran, A. O. and Gbadamosi, K. T. "Concessioning a Strategy for Enhancing Nigeria's Airport Operational Efficiency - Lessons from Developed Countries", International Journal of Research in Industrial Engineering, Vol. 6, Number 3, 2017, pp 228-245.

[12] Washington State Department, Airport Maintenance Guidelines, WSDOT Manual Publications, 2011.

[13] Ogunsiji, A. S., \& Ogunsiji, O. O. "Consummate precision of strategic management approach on transport logistics and physical distribution for port performance efficiency: A case study of Nigerian Ports", Journal of emerging trends in economics and management sciences, Vol. 1, Number 2, 2010, pp 96-101.

[14] Agabi Chris. "October wait for Abuja airport's new terminal begins" www.dailytrust.com.ng /octoberwait-for-Abuja-airport-s-new-terminal-begins262992.html, Accessed on July 28, 2018.

[15] Federal Airports Authority of Nigeria (FAAN). www.faan.gov.ng, Accessed on June 12, 2018

[16] Ogundolapo Ola. Modernizing the Port Harcourt International Airport: A Floodlight on the Ebele Okoye Administration, John Archers (Publishers) Ltd., Nigeria, 2014

[17] Bryman, A. and Bell, E. Business Research Methods, Second Edition, Oxford: Oxford University Press, 2007

[18] Biggs D. C., Bol M. A., Baker J., Gosling G. D., Franz J. D., and Cripwell J. P. "Guidebook for Conducting Airport User Surveys", The National Academies of Sciences, Engineering, Medicine, www.nap.edu/14333, Accessed on August 10, 2018.

[19] McBurney, D. and White, T. Research Methods, Wadsworth Cengage Learning, Belmont, 2010.

[20] Ugwu O. O., Okafor C. C., and Nwoji C. U. "Assessment of Building Maintenance in Nigerian University System: A Case Study of University Of Nigeria, Nsukka", Nigerian Journal of Technology (NIJOTECH) Vol. 37, No. 1, January 2018, pp. $44-$ 52.

[21] Eke Emmanuel Chidi, Musa Shamsudeen, Fashubaa Taiwo Oladipupo, and Abass Jimoh Owolabi. "An assessment of maintenance culture on public buildings in Nigeria (a case study of Osun state)", IOSR Journal of Mechanical and Civil Engineering (IOSR-JMCE), Volume 14, Issue 5 Ver. III (Sep. - Oct. 2017), pp. 53-57.

[22] O'Connell Ann .A. Logistic Regression Models for Ordinal Response Variables, Sage Publications, International Educational and Professional Publisher Thousand Oaks London, 2016 